\title{
Analysis of the difference between the test and production in Well Z202-H1
}

\author{
Lei Zhian ${ }^{1,6}$, MAO Zhenglin²,6,a*, QI Lin ${ }^{3}$, Zheng Jian ${ }^{4}$, Zhang Haijie ${ }^{1}$, Xie Wei $^{5}$ \\ ${ }^{1}$ Chongqing Shale Gas Exploration and Development Co., Ltd., Chongqing, China \\ ${ }^{2}$ State Key Lab Of Oil And Gas Reservoir Geology And Exploitation (Southwest Petroleum University), Chengdu, P.R. China \\ ${ }^{3}$ Geology Exploration and Development Research Institute, CNPC Chuanqing Drilling Engineering Co., Ltd., Chengdu, Sichuan 610051, \\ China \\ ${ }^{4}$ Sichuan Changning Natural Gas Development Co.,Ltd., Chengdu, Sichuan 610056,China \\ ${ }^{5}$ Sichuan Shale Gas Exploration and Development Co., Ltd., Chengdu,610051, China \\ ${ }^{6}$ Key Laboratory of Seepage and Rock Mechanics of Oil and Gas Wells in Shanxi Province, Xian 710000, China
}

\begin{abstract}
In recent years, shale gas in the Upper Ordovician Wufeng Formation and lower Silurian Longmaxi Formation is gradually developing into deep strata in Sichuan Basin. Well 202-H1 is a evaluation well deployed to evaluate the productivity of horizontal Wells in longmaxi Formation and Wufeng Formation in The West Chongqing block. The well type is horizontal well. The main reasons for the poor production effect of Well Z202-H1 are as follows: Reservoir pores are not developed; continuous thickness of thin reservoir; insufficient fracturing treatment; low flowback rate, large water production and wellbore fluid accumulation. This article not only obtained the reasons for the difference between the test and production of well Z202-H1, but also provided a new research idea for the test and production tracking analysis of deep shale gas static in The Western Chongqing block.
\end{abstract}

\section{Introduction}

At present, the shale gas from Wufeng Formation to Longmaxi Formation in Sichuan Basin has realized scale benefit development in the middle and shallow layers such as Changning, Weiyuan and Jiaoshi Dam (with a buried depth of $3500 \mathrm{~m}$ to $500 \mathrm{~m}$ ), and is gradually expanding to the deep layers such as Luzhou and Western Chongqing (with a buried depth of 3500-4500 m ${ }^{[1-5]}$. Well Z202-H1 is an evaluation well deployed in order to evaluate the productivity of horizontal Wells from Longmaxi formation to Wufeng Formation in the east flank of the north aoding formation in The West Mountains in The West Chongqing Block. The well type is horizontal, and longmaxi formation and Wufeng Formation are the target zones. The test output of the well was 456,700 cubic meters per day, which was the first shale gas well with commercial value obtained by petrochina in Chongqing. However, after the well was put into production, the output and pressure dropped fast, and the production condition was poor.

Taking Well 202-H1 as the research object, this paper analyzes the main reasons for the difference between well Z202-H1 and production from the aspects of reservoir geological characteristics, fracturing effect and production data, etc.

\section{The main factors of high yield when testing}

\subsection{Natural fracture development}

Well Z202-H1 is located on the east wing of the West Mountain anticline, with Plutonic syncline developed to the east and Meida syncline to the west ${ }^{[6]}$. According to the electrical survey, there were 4 open seam and 44 filling seam, which were mainly developed in Longmaxi Formation 2, Longmaxi Formation 1-2, and Wufeng Group. The pressure coefficient of well Z202-H1 is 1.90 . Under the background of abnormal high pressure, the development of natural fractures in the reservoir is conducive to the accumulation of free gas. Under the appropriate construction conditions, high production is easy to be obtained ${ }^{[7]}$.

\subsection{Reservoir parameters are excellent}

By predecessors' statistical analysis of luzhou block shale gas production test, the test of horizontal well production not only with reservoir thickness, reservoir parameters, also with the length of horizontal well trajectory in reservoir of I type (figure 1$)^{[8,9]}$. When the thickness of reservoir of I type is larger, reservoir of I type drilling encounter, the longer the length of gas well and the higher 
initial production. the length of horizontal well trajectory in reservoir of I type is $1370.3 \mathrm{~m}$, the thickness is $9.3 \mathrm{~m}$, the average porosity of reservoir is $3.4 \%$, the average permeability is $56 \mathrm{md}$, the water saturation is $25.9 \%$, the average gas content is $5.0 \mathrm{~m}^{3} / \mathrm{t}$, the brittleness index is 50.9 on average.Compared with other shale gas well (table 1), the length of horizontal well trajectory in reservoir of I type is higher, and reservoir parameter is better.

Table 1. Shale gas well parameters comparison table

\begin{tabular}{c|c|c|c|c|c|c}
\hline Project Compared & Z201 - H1 Wells & Z202 - H1 Wells & Z203 Wells & Z201 Wells & CNH6-3 Wells & CN H6-4 Wells \\
\hline The testing production & 10.6 & 45.7 & 14.6 & 14.0 & 15.5 & 30.6 \\
\hline Water saturation & 40.0 & 25.9 & 21.6 & 33.8 & 42.9 & 27.5 \\
\hline The total gas content & 7.2 & 5.0 & 5.2 & 5.2 & 4.1 & 4.6 \\
\hline Brittleness index & 49.1 & 50.9 & 43.7 & 51.9 & 50.2 & 50.5 \\
\hline $\begin{array}{c}\text { The length of } \\
\text { horizontal well } \\
\text { trajectory in reservoir } \\
\text { of I type }\end{array}$ & 1449.9 & 1370.3 & 1492.0 & 974.0 & 1388.0 & 1388.0 \\
\hline
\end{tabular}

\section{Main reasons for poor production rate}

\subsection{According to core analysis, reservoir pores do not develop}

By comparison with previous yuxi, changning, vying with luzhou microscopic pore block face rate is found (figure
2), chongqing west block reservoir porosity development are weaker, which makes reservoir matrix produce shale gas relatively slowly, slower matrix to the supply of the fracture, and so on Z202 - H1 early gas production Wells is too big, in the free gas produced after formation of undersupply leads to rapid decline in capacity. By comparing the Z201-H1 well in the same block, it is found that the Z201-H1 well adopts low gas production capacity and has a good stable production capacity.

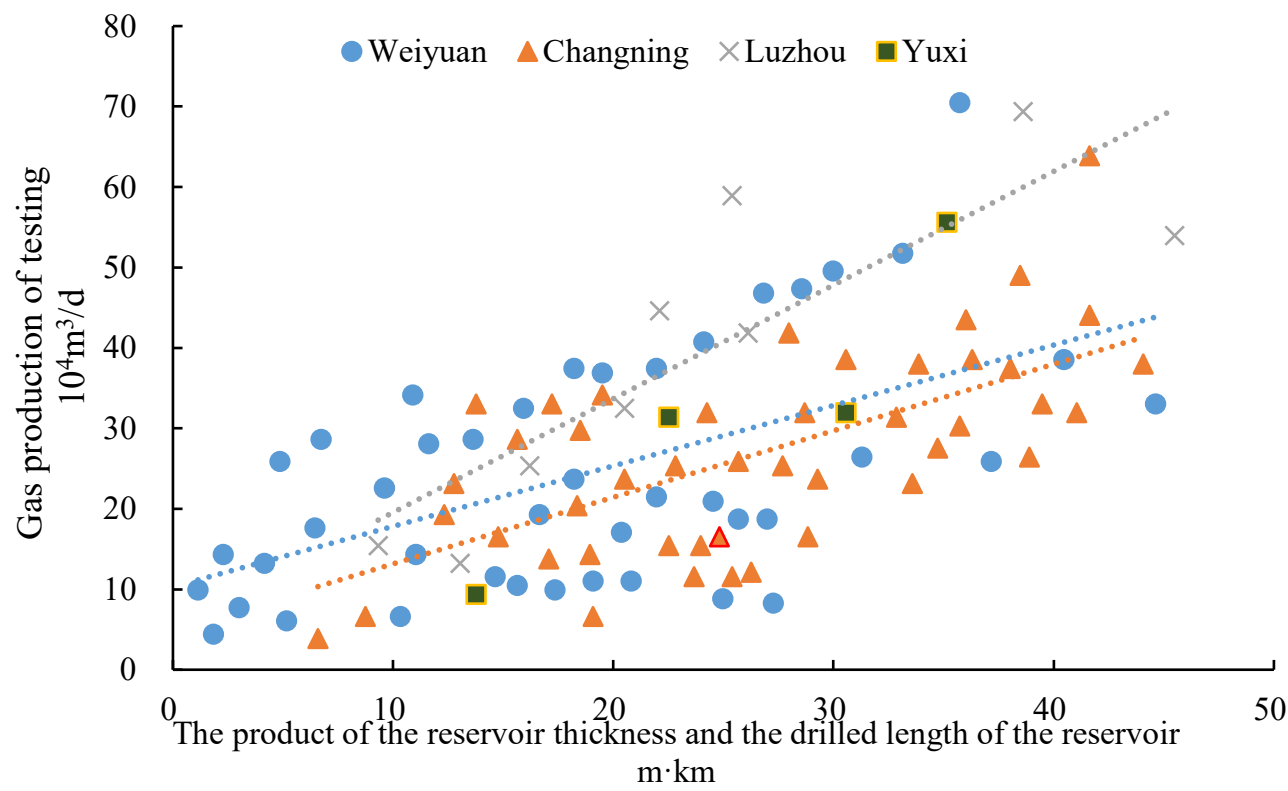

Fig1. Correlation diagram between shale gas well test gas production and Class I reservoirs 


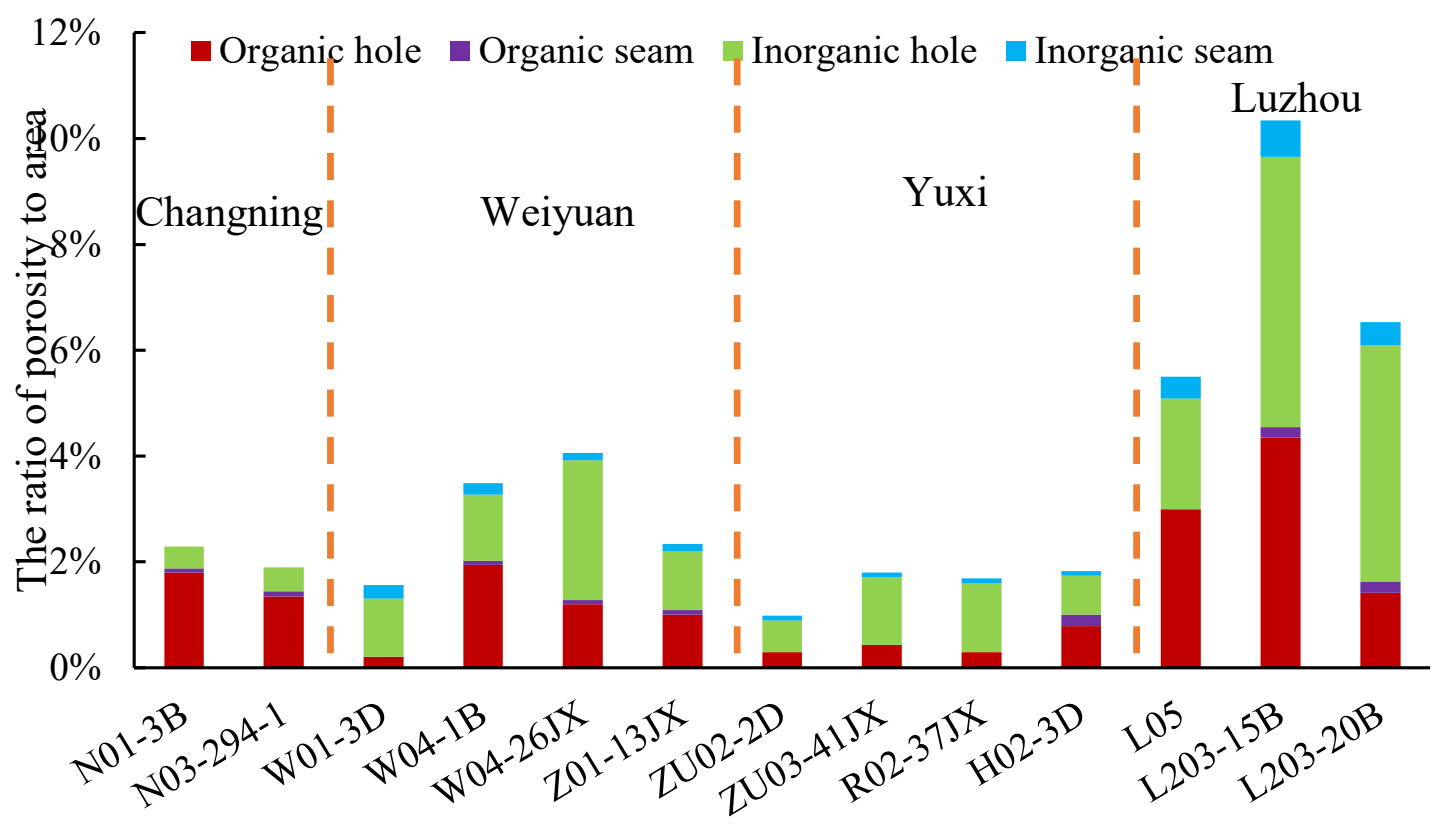

Fig2. Histogram of microscopic pore face rate in south Sichuan region

\subsection{The thin thickness of reservoir}

A small layer of Longmaxi Formation 1 in the Z202-H1 well is 2.4 meters thick, which is much lower than the adjacent well (Table 2). Based on multistage fracturing horizontal well productivity formula analysis, reservoir thickness value is smaller, the sooner pressure wave will pass to the border of the system, the greater the wellbore reservoir in the transitional period of concave child, the shorter the duration of hydraulic fracture linear flow around the stage, with fewer reservoir thickness value, can also lead to hydraulic fracture of radial flow around more and more is not obvious, so that the substrate interporosity flow occurred much earlier ${ }^{[10,11]}$. The thinner the reservoir, the lower the output per well and the faster the production decline.

Table 2 Log interpretation results of Western Chongqing

\begin{tabular}{|c|c|c|c|c||c|c|c|c|}
$\begin{array}{c}\text { Well } \\
\text { no. }\end{array}$ & horizon & $\begin{array}{c}\text { Top depth } \\
(\mathrm{m})\end{array}$ & $\begin{array}{c}\text { At the end of } \\
\text { deep }(\mathrm{m})\end{array}$ & $\begin{array}{c}\text { Thickness } \\
(\mathrm{m})\end{array}$ & $\begin{array}{c}\text { Porosity } \\
(\%)\end{array}$ & $\begin{array}{c}\text { Water } \\
\text { saturation }(\%)\end{array}$ & $\begin{array}{c}\text { Total organic } \\
\text { carbon }(\%)\end{array}$ & $\begin{array}{c}\text { Total gas } \\
\text { content }\left(\mathrm{m}^{3} / \mathrm{t}\right)\end{array}$ \\
\hline \multirow{2}{*}{ Z202 } & $\begin{array}{c}\text { Longmaxi } \\
\text { Formation 11 }\end{array}$ & 3888.80 & 3891.20 & 2.4 & 3.4 & 23.5 & 4.5 & 5.7 \\
\cline { 2 - 9 } & Wufeng Group & 3891.20 & 3898.10 & 6.9 & 3.4 & 28.4 & 3.0 & 4.9 \\
\hline \multirow{2}{*}{ Z203 } & $\begin{array}{c}\text { Longmaxi } \\
\text { Formation 11 }\end{array}$ & 4096.50 & 4102.90 & 6.4 & 5.4 & 37.5 & 4.5 & 6.5 \\
\cline { 2 - 10 } & Wufeng Group & 4102.90 & 4108.70 & 5.8 & 4.5 & 39.6 & 2.4 & 5.3 \\
\hline \multirow{2}{*}{ Z205 } & $\begin{array}{c}\text { Longmaxi } \\
\text { Formation 11 }\end{array}$ & 3345.40 & 3350.60 & 5.2 & 5.4 & 30.2 & 5.4 & 6.5 \\
\cline { 2 - 10 } & Wufeng Group & 3350.60 & 3356.50 & 5.9 & 4.4 & 35.0 & 2.2 & 4.8 \\
\hline \multirow{2}{*}{ Z206 } & $\begin{array}{c}\text { Longmaxi } \\
\text { Formation 11 }\end{array}$ & 4266.00 & 4270.10 & 4.1 & 5.1 & 30.1 & 4.8 & 6.4 \\
\cline { 2 - 10 } & Wufeng Group & 4270.10 & 4276.00 & 5.9 & 4.4 & 34.1 & 2.5 & 5.3 \\
\hline
\end{tabular}

\subsection{Insufficient fracture reconstruction, low fracture complexity and failure to communicate with the remote end during the process.}

In order to maximize the fracturing effect of horizontal Wells in shale oil and gas, only by increasing the complexity of fractures as much as possible can the maximum volume of fracturing be achieved within the affected range of fractures, and the effect of fracturing of horizontal Wells and the economy of subsequent development be improved ${ }^{[12]}$. However, it is very difficult to effectively transform deep shale reservoir under the conditions of high temperature, high pressure and high ground stress by volume fracturing to form network fractures similar to medium-shallow shale ${ }^{[13]}$. The fracture complexity index in all sections of well Z202-H1 is low, and most of them are complex fractures (FIG. 3), indicating poor fracturing effect and failure to communicate with distal fractures. 


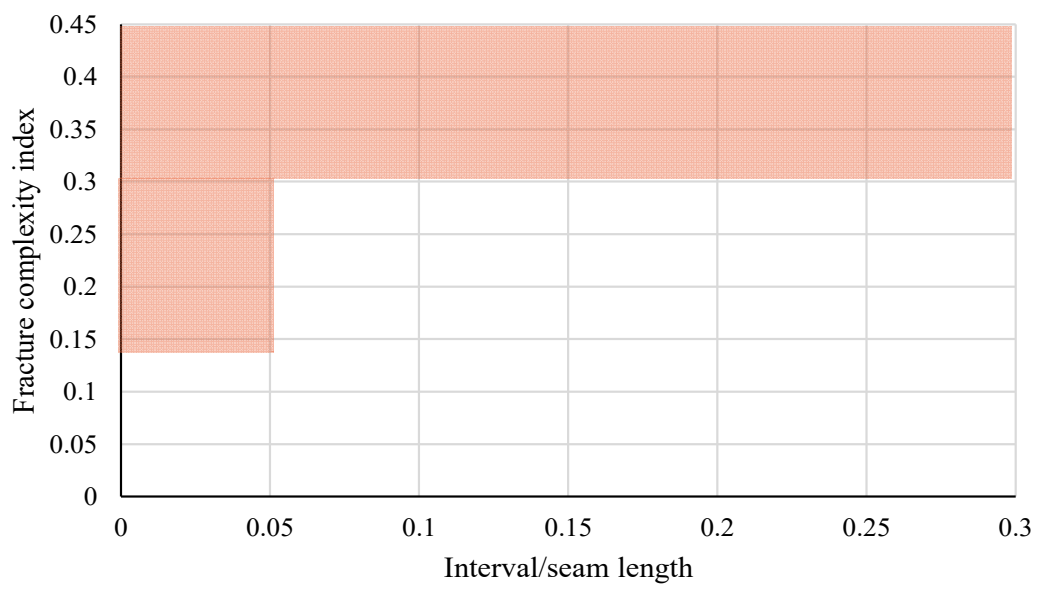

Fig3. Complex exponential distribution of fractures in well Z202-H1

\subsection{Low backflow rate in the drainage stage and fracturing fluid retention formation}

In the Z202-H1 well, the wellbore was blocked during drainage, resulting in difficulties in drainage, with a drainage rate of only $4.07 \%$. Too much fracturing fluid stays in the formation, resulting in large gas well water production and fast formation energy consumption. After the pressure drops, gas production fails to meet the critical fluid carrying requirements, resulting in wellbore fluid accumulation.

The average gas yield of the tubing in Z202-H1 well was $35,000 \mathrm{~m}^{3} /$ day and the average water yield was 28 $\mathrm{m}^{3} /$ day. According to the formula of the critical fluid carrying rate of the gas well, the change of the critical fluid carrying rate of the well along with the depth measurement was calculated (Figure 4). It can be seen that the inclined section of the well did not meet the critical fluid carrying requirement, which was easy to cause overstock. The production data showed that the oil casing pressure difference of tubing production was $6 \mathrm{MPa}$, and the gas production capacity fluctuated. The fluid accumulation height of gas well was calculated by the oil casing pressure difference method to be about $3500 \mathrm{~m}$, and the well inclination was about $30^{\circ}$.

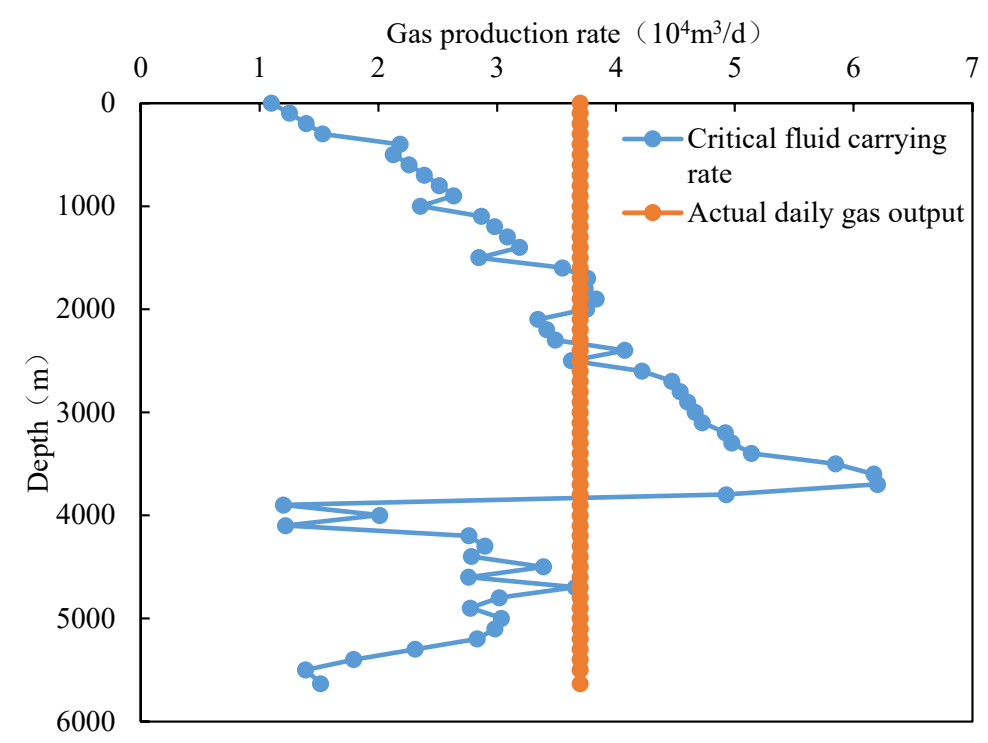

Fig4. Changes of critical wellbore fluid flow in well 202-H1

\section{Conclusion}

(1) Based on the analysis of reservoir geological characteristics, fracturing effect, and production data, the characteristics of adjacent Wells and other blocks were compared, and the main reasons for the difference between well testing and production in well Z202-H1 were obtained, providing a new idea for deep shale gas well testing and production tracking analysis in The Western Chongqing block.

(2) The reasons of Z202 - H1 well testing high yield are: the main factors of the reservoir, natural fracture development I reservoir drilling in high class, reservoir parameter. 
(3) The main reason for the poor production effect of Z202-H1 is that the reservoir pores do not develop. I continuous thickness of thin reservoir; Insufficient fracture reconstruction, low fracture complexity, failure to communicate with the remote end in the process; Low backflow rate in the drainage stage leads to large water production in the production stage, resulting in wellbore effusion.

\section{References}

1. Zhang J C, Nie H K, XU B, JIANG S L, ZHANG P $X$, Wang Z Y. (2008). Geological conditions of shale gas reservoir in Sichuan Basin. Natural Gas Industry, 151-156+179-180.

2. Ma X H. (2008). Enrichment rule and Scale effective exploitation of shale gas in the southern Sichuan Basin.Natural Gas Industry,38(10):1-10.

3. Long S X, FENG J J, LI F X, DU W. (2012).Prospects of deep Marine shale gas exploration and development in the south of Sichuan Basin. Natural Gas Geoscience, 29(04):443-451.

4. Ma X H, XIE J. (2015). Progress and Development Prospect of Shale gas exploration and Development in south Sichuan region. Petroleum Exploration and Development, 45(01):161-169.

5. Zhang C L, Zhang J, Li W G, et al. (2019).Deep shale reservoir characteristics and exploration prospect of Wufeng-Longmaxi Formation in Dazu Block, Western Chongqing .Natural gas geoscience, 30(12):1794-1804.

6. Li Z, Jia C G, Yang C H, et al. (2015).Journal of rock mechanics and engineering, 34(01):12-20.

7. Yang H Z, ZHAO S X, Liu Y, etc. (2019).Main controlling factors of deep shale gas enrichment and high yield in luzhou block. Natural gas industry, 39(11):55-63.

8. Xie J, Zhao S X, Shi X W, et al., (2017).geological controlling factors for high yield of horizontal shale gas Wells in Sichuan Basin.Natural gas industry, 37(07):1-12.

9. Jiang T X. (2013). Research and Application prospect of fracture Complexity index in horizontal Wells of shale oil and gas.Oil drilling technology, 41(02):7-12.

10. Xie Y X, LIU Q G, WANG W H, LI R Y, HU X H. (2016).Daqing petroleum geology and development, 35(05):163-169.

11. Guo Y D, Hu X H, Wang W H, etc. (2015).Numerical Simulation of seepage characteristics of multi-stage fractured horizontal Wells in Shale gas. Petrochemical Technology,25(03):153-156.

12. Jiang T X, Zhou J, Zhang X et al. (2017).Research and prospect of fracture propagation and diversion characteristics in deep shale gas Wells . Chinese science: physics, mechanics and astronomy, 47(11):33-40.

13. Tan X H, Li X P. (2013).A new model of gas well considering the influence of continuous liquid carrying and droplet diameter . Hydrodynamic research and progress series A,28(01):41-47. 